\title{
Chronic Antidepressant Administration Increases the Expression of cAMP-Specific Phosphodiesterase 4A and 4B Isoforms
}

\author{
Michihiro Takahashi, ${ }^{1}$ Rose Terwilliger, ${ }^{1}$ Caryl Lane, ${ }^{3}$ Peter S. Mezes, ${ }^{3}$ Marco Conti, ${ }^{2}$ and Ronald S. Duman ${ }^{1}$ \\ ${ }^{1}$ Laboratory of Molecular Psychiatry, Departments of Psychiatry and Pharmacology, Yale University School of Medicine, \\ Connecticut Mental Health Center, New Haven, Connecticut 06508, 2Division of Reproductive Biology, Department of \\ Gynecology and Obstetrics, Stanford University Medical Center, Stanford, California 94305, and ${ }^{3}$ Central Research \\ Division, Pfizer Inc., Groton, Connecticut 06340
}

The influence of chronic antidepressant administration on expression of the three major phosphodiesterase (PDE) 4 subtypes found in brain (PDE4A, PDE4B, and PDE4D) was examined. The treatments tested included representatives of four major classes of antidepressants: selective reuptake inhibitors of serotonin (sertraline and fluoxetine) or norepinephrine (desipramine), a monoamine oxidase inhibitor (tranylcypromine), and electroconvulsive seizure. Expression of PDE4A and PDE4B, but not PDE4D, mRNA and immunoreactivity were significantly increased in rat frontal cortex by chronic administration of each of the four classes of antidepressants. We also found that antidepressant administration significantly increased the expression of PDE4B mRNA in the nucleus accumbens, a brain region thought to mediate pleasure and reward that could also contribute to the anhedonia often observed in depressed patients. In contrast, expression of PDE4A and PDE4B were not influenced by short-term treatment ( 1 or $7 \mathrm{~d}$ ) and were not influenced by chronic administration of nonantidepressant psychotropic drugs (cocaine or haloperidol), demonstrating the time dependence and pharmacological specificity of these effects. Upregulation of PDE4A and PDE4B may represent a compensatory response to antidepressant treatment and activation of the cAMP system. The possibility that targeted inhibition of these PDE4 subtypes may produce an antidepressant effect is discussed.

Key words: phosphodiesterase; frontal cortex; nucleus accumbens; sertraline; desipramine; electroconvulsive seizure; serotonin; norepinephrine
Although antidepressant drugs are widely prescribed for a variety of affective illnesses, the molecular and cellular adaptations that underlie the therapeutic action of these treatments have remained obscure. Moreover, the targets for development of therapeutic agents have remained primarily unchanged over the past 40 years (i.e., inhibition of monoamine reuptake and metabolism). Recent studies have demonstrated adaptations at several levels of the cAMP signal transduction cascade in response to antidepressant treatments, including increased coupling of stimulatory G-protein and adenylyl cyclase (Ozawa and Rasenick, 1991), increased levels of cAMP-dependent protein kinase (Nestler et al., 1989; Perez et al., 1989, 1991), and increased expression and function of the cAMP response element binding protein (CREB) (Nibuya et al., 1996). These findings support the hypothesis that the action of antidepressant treatment is mediated, in part, by increased function of the cAMP signal transduction cascade (Duman et al., 1997).

The possibility that the cAMP system is involved in the mechanism of action of antidepressants is supported by basic and clinical studies of inhibitors of phosphodiesterase (PDE), the enzyme responsible for metabolism of cAMP. Preclinical studies demonstrate that PDE inhibitors have antidepressant-like effects in behavioral models (Wachtel and Schneider, 1986; Griebel et

Received July 23, 1998; revised Oct. 26, 1998; accepted Oct. 29, 1998.

This work is supported by United States Public Health Service Grants MH45481, MH53199, and 2 PO1 MH25642, and by a Veterans Administration National Center Grant for Posttraumatic Stress Disorder, VA Medical Center. We would also like to thank Dr. Carol D'Sa for analysis of gene sequence and helpful discussion.

Correspondence should be addressed to Ronald S. Duman, 34 Park Street, New Haven, CT 06508.

Copyright (C) 1999 Society for Neuroscience $\quad 0270-6474 / 99 / 190610-09 \$ 05.00 / 0$ al., 1991; O’Donnell, 1993). Moreover, clinical trials demonstrate that rolipram, a specific inhibitor of the high-affinity cAMP PDE (PDE4), has antidepressant efficacy in depressed patients (Horowski and Sastre-Y-Hernandez, 1985; Bobon et al., 1988; Fleischhacker et al., 1992). Treatment with papaverine, a nonspecific PDE inhibitor, was also found to have antidepressant efficacy in a case report (Malison et al., 1997). However, the clinical use of PDE inhibitors as antidepressants has been limited because of their side effects, most notably nausea.

The molecular identification of several different PDE4 subtypes raises the possibility that there is one isoform that mediates the antidepressant action of rolipram but not the side effects. Within the PDE4 family, which is one of at least nine major PDE families, there are four subtypes, referred to as PDE4A-PDE4D (Beavo, 1994; Conti et al., 1995; Conti and Jin, 1999). Three of these (PDE4A, PDE4B, and PDE4D) are expressed at relatively high levels in brain, whereas the fourth subtype (PDE4C) is very low or not present in most brain regions (Engels et al., 1995; Iona et al., 1998).

In the present study, we examined the influence of chronic antidepressant treatment on the expression of PDE4 isoforms in brain in an attempt to identify a subtype(s) that is involved in antidepressant action. This approach is based on the finding that expression of PDE4 is induced by activation of the cAMP system (for review, see Conti et al., 1995; Conti and Jin, 1999) and that antidepressant treatment activates the cAMP cascade. This suggests that the relevant PDE4 isoform(s) would be upregulated by antidepressant treatment. In support of this possibility, a recent study has demonstrated that PDE4A immunoreactivity is increased by administration of desipramine (Ye et al., 1997). The 
present study extends this work by demonstrating that levels of PDE4A and PDE4B, but not PDE4D, are upregulated by several different classes of antidepressant treatment but not by nonantidepressant psychotropic drugs.

\section{MATERIALS AND METHODS}

Animals and treatment paradigms. Male Sprague Dawley rats (150-200 gm) (CAMM, Wayne, NJ) were group housed and maintained on a $12 \mathrm{hr}$ light/dark cycle with food and water available ad libitum. All treatments were according to standard protocols as described previously (Nibuya et al., 1995, 1996). Rats were administered (once daily) electroconvulsive seizure (ECS) via earclip electrodes $(50 \mathrm{~mA}, 0.3 \mathrm{sec})$ or received sham treatment (handled identically as those that received ECS but without electrical stimulation). For drug treatments, groups of rats were administered tranylcypromine $(7.5 \mathrm{mg} / \mathrm{kg}$ for $7 \mathrm{~d}$, then $10 \mathrm{mg} / \mathrm{kg}$ for $7 \mathrm{~d}$ ), desipramine $(15 \mathrm{mg} / \mathrm{kg})$, sertraline $(10 \mathrm{mg} / \mathrm{kg})$, fluoxetine $(5 \mathrm{mg} / \mathrm{kg})$, haloperidol $(2 \mathrm{mg} / \mathrm{kg})$, cocaine $(15 \mathrm{mg} / \mathrm{kg})$, or vehicle (DMSO for all treatments) once daily for $14 \mathrm{~d}$ via intraperitoneal injection. Animals were decapitated $3 \mathrm{hr}$ after the last treatment in all cases, except for ECS in which animals were decapitated $2 \mathrm{hr}$ after the last ECS treatment. Brains were removed and frozen immediately on dry ice for in situ hybridization, or sections of frontal cortex and hippocampus were dissected and frozen on dry ice for either Northern blot or immunoblot analysis as described below. All animal use procedures were in strict accordance with the National Institutes of Health Guide for the Care and Use of Laboratory Animals and were approved by the Yale Animal Care and Use Committee. The drugs used for these studies were obtained from the following sources: tranylcypromine, desipramine, and haloperidol were purchased from Sigma (St. Louis, MO); fluoxetine was provided by Lilly Research Laboratories (Indianapolis, IN); sertraline was obtained from Pfizer Central Research (Groton, CT); and cocaine was obtained from the National Institute on Drug Abuse (Baltimore, MD).

In situ hybridization analysis. Analysis of PDE4A, PDE4B, and PDE4D mRNA by in situ hybridization was conducted as described previously by this laboratory (Nibuya et al., 1995). PDE4A-, PDE4B-, and PDE4Dspecific cDNA clones were used to generate ${ }^{35} \mathrm{~S}$-labeled riboprobes. Coronal brain sections were hybridized with ${ }^{35} \mathrm{~S}$-labeled PDE4 subtype riboprobes $\left(10^{6} \mathrm{cpm} / \mathrm{section}\right)$ for $18 \mathrm{hr}$ at $55^{\circ} \mathrm{C}$ in buffer containing $50 \%$ formamide, $0.6 \mathrm{M} \mathrm{NaCl}, 10 \mathrm{~mm}$ Tris, $1 \times$ Denhardt's solution, $2 \mathrm{~mm}$ EDTA, $10 \mathrm{~mm}$ DTT, $10 \%$ dextran sulfate, $50 \mu \mathrm{g} / \mathrm{ml}$ salmon sperm DNA, and $250 \mathrm{mg} / \mathrm{ml}$ tRNA. The sections were washed in $2 \times \mathrm{SSC}$ at $25^{\circ} \mathrm{C}$ and then treated with $20 \mu \mathrm{g} / \mathrm{ml} \mathrm{RNase}$ A for $45 \mathrm{~min}$ in $0.5 \mathrm{M} \mathrm{NaCl}, 10 \mathrm{~mm}$ Tris, and $1 \mathrm{~mm}$ EDTA. The sections were then washed twice in $0.2 \times$ SSC at $55^{\circ} \mathrm{C}, 30 \mathrm{~min}$ per wash. The sections were dried, exposed to Hyperfilm (Amersham, Arlington Heights, IL), and subsequently counterstained with cresyl violet to allow alignment with the autoradiogram. The specificity of the hybridization was confirmed by demonstrating that ${ }^{35} \mathrm{~S}$ labeled sense PDE4A, PDE4B, and PDE4D riboprobes did not yield any significant hybridization (data not shown).

Northern blot analysis. Total RNA was isolated from sections of frontal cortex or hippocampus by the guanidine isothiocyanate-cesium chloride centrifugation method, and levels of PDE4 subtype mRNA was determined by Northern blot analysis (Nibuya et al., 1995). PDE4A, PDE4B, and PDE4D cDNA clones were used to generate ${ }^{32} \mathrm{P}$-labeled riboprobes. Briefly, $20 \mu \mathrm{g}$ of total RNA was electrophoresed on a 1\% agarose gel, and the RNA was transferred to nitrocellulose filters. The resulting filters were then incubated with the ${ }^{32} \mathrm{P}$-labeled PDE4 riboprobes for $18 \mathrm{hr}$ at $65^{\circ} \mathrm{C}$ and washed in $2 \times \mathrm{SSC}(0.15 \mathrm{M} \mathrm{NaCl}$ and $0.015 \mathrm{M}$ sodium citrate, $\mathrm{pH}$ 7.0 ) and $0.1 \%$ SDS at $65^{\circ} \mathrm{C}$ for $30 \mathrm{~min}$, and then twice in $0.2 \times \mathrm{SSC}$ and $0.1 \% \mathrm{SDS}$ at $65^{\circ} \mathrm{C}$ for $60 \mathrm{~min}$. Levels of total RNA for each lane were determined by reprobing the nitrocellulose filters with a ${ }^{32} \mathrm{P}$-labeled cyclophilin cDNA probe, which was radiolabeled using a random prime kit (Stratagene, La Jolla, CA). The radiolabeled mRNA bands were visualized by autoradiography and quantified with a laser densitometer. The level of PDE4 subtype mRNA was normalized to cyclophilin mRNA levels to account for differences in the amount of RNA per lane.

Immunoblot analysis. After decapitation, brains were removed rapidly, and the frontal cortex and hippocampus were dissected and frozen on dry ice. The hippocampus was homogenized $(50 \mathrm{mg}$ wet weight $/ \mathrm{ml})$ in $1 \%$ SDS, and each sample (10-40 $\mu \mathrm{g}$ of protein) was subjected to SDSPAGE as described previously (Beitner-Johnson et al., 1992). Final concentrations of samples were adjusted to contain the following: $50 \mathrm{~mm}$ Tris, $\mathrm{pH}$ 6.7, $4 \%$ glycerol, $4 \%$ SDS, $2 \% \beta$-mercaptoethanol, and bromophenol blue as a marker. Samples were boiled for $3 \mathrm{~min}$ and loaded onto
$7.5 \%$ acrylamide $-0.8 \%$ bisacrylamide resolving gels. Proteins in gels were then electrophoretically transferred to nitrocellulose. After electrophoretic transfer, the nitrocellulose filters were incubated in immunoblot buffer [ $2 \%$ milk in a buffer containing $10 \mathrm{~mm}$ sodium phosphate, $\mathrm{pH} 7.2$, $140 \mathrm{~mm} \mathrm{NaCl}$, and $0.05 \%$ Tween 20 (Sigma)]. The filters were probed with monoclonal antibodies directed against PDE4A-PDE4D recombinant protein at a dilution of $1 \mu \mathrm{g} / \mathrm{ml}$. Murine monoclonal antibodies were generated against baculovirus-expressed recombinant PDE4A-PDE4D proteins. Each antibody has been shown to be specific for its respective PDE4 isozyme in that there is no cross-reactivity with other PDE4 recombinant protein. The filters were then incubated with goat antimouse antibody (1:2000) conjugated with horseradish peroxidase (Vector Laboratories, Burlingame, CA). The nitrocellulose filters were developed using the enhanced chemiluminescence system and exposed to Hyperfilm (Amersham). For the blocking experiments, each antibody was preincubated with its corresponding recombinant protein at a concentration of $1 \mathrm{mg} / \mathrm{ml}$ antibody and $10 \mathrm{mg} / \mathrm{ml}$ recombinant protein for 2 $\mathrm{hr}$ at room temperature. The antibody was then diluted in immunoblot buffer and incubated with nitrocellulose filters as described above.

Data analysis. Levels of PDE4 mRNA were determined by outlining the band on Northern blots or the regions of interest on in situ hybridization sections, which were then quantified on the MacIntosh-based NIH Image analysis program (version 1.52); an equivalent area on each Northern blot or brain section was outlined for the various samples. ${ }^{14} \mathrm{C}$ step standards were used to verify the linearity of densitometry. For in situ hybridization sections, the following regions were analyzed: frontal cortex (see Results), nucleus accumbens, dentate gyrus granule cell layer, and CA 3 and CA1 pyramidal cell layers. For each animal, both sides of two individual brain sections were analyzed, for a total of four determinations, and the mean \pm SEM was determined. The results were then subjected to statistical analysis. Experiments containing three groups or more (see Animal and treatment paradigms) were subjected to a one-way ANOVA, with a significance level of $p<0.05$, and Fisher's post hoc test Experiments containing two groups were subjected to Student's $t$ test, with significance determined at the $p<0.05$ level.

\section{RESULTS}

\section{Regulation of PDE4 isoform mRNA by antidepressant} treatment: in situ hybridization analysis

Riboprobes specific for the different PDE4 isoforms were used to examine the distribution and regulation of PDE4A, PDE4B, and PDE4D in brain (Fig. 1). Expression of PDE4A was observed in deep layers of cerebral cortex and the major subfields of hippocampus (dentate gyrus granule cell layer, CA3 and CA1 pyramidal cell layers). PDE4B mRNA is expressed in the more superficial layers of frontal and parietal cortex and is expressed at much lower levels in the hippocampus (i.e., there is little or no expression in the dentate gyrus granule cell layer). PDE4D is expressed at relatively high levels in deep layers of cerebral cortex and hippocampus. These expression patterns are similar to those reported in a previous study for PDE4A, PDE4B, and PDE4D (Engels et al., 1995). The PDE4C isoform is not expressed in any brain region examined, with the exception of the olfactory bulb (Swinnen et al., 1989a; Engles et al., 1995).

We next examined the influence of antidepressants on expression of the PDE4 isoforms. Chronic antidepressant administration (10 d for ECS and $14 \mathrm{~d}$ for antidepressant drugs) significantly increased the expression of PDE4A and PDE4B, but not PDE4D, mRNA in frontal cortex (Fig. 1). The antidepressants tested included a norepinephrine selective reuptake inhibitor (desipramine), two serotonin selective reuptake inhibitors (fluoxetine and sertraline), a monoamine oxidase inhibitor (tranylcypromine), and ECS. A similar upregulation of PDE4A and PDE4B was observed in parietal cortex but not in the dentate gyrus granule cell layer or CA3 and CA1 pyramidal cell layers of hippocampus (Fig. 1).

Expression of the three PDE4 isoforms was also examined in the nucleus accumbens, a brain region involved in reward. The 
PDE4A
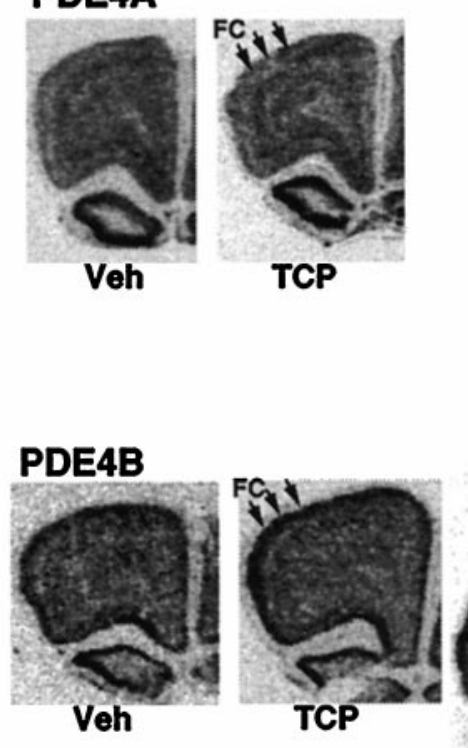

\section{PDE4D}

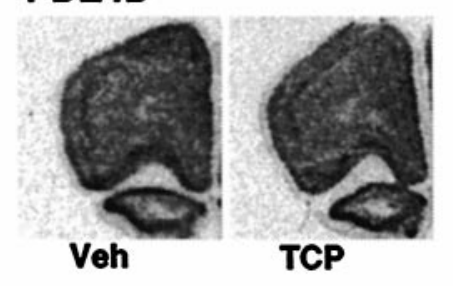

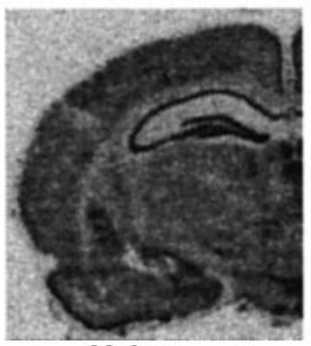

Veh

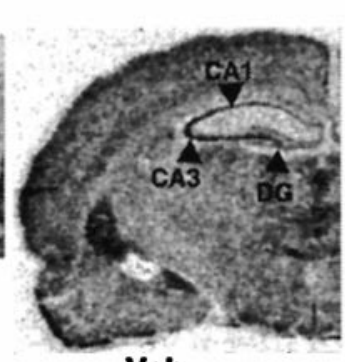

Veh

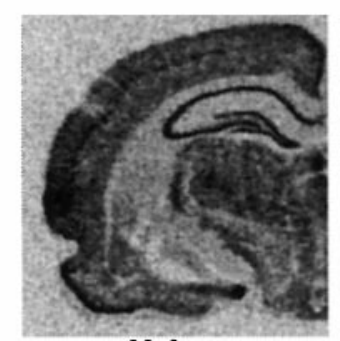

Veh

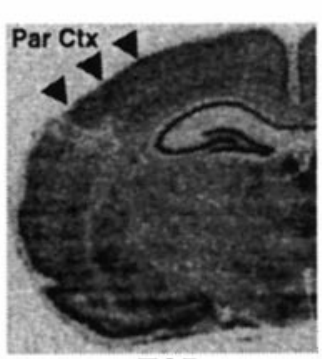

TCP
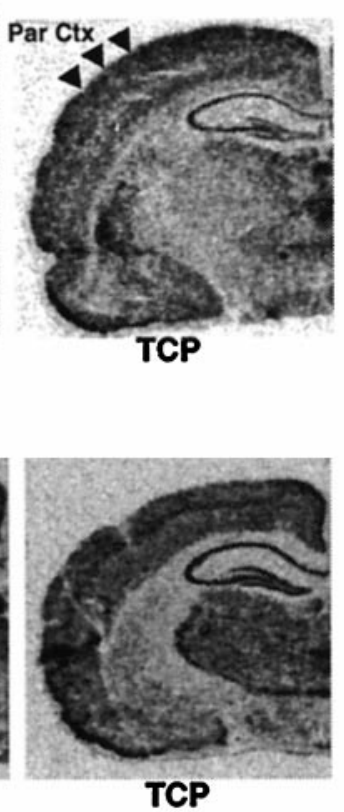
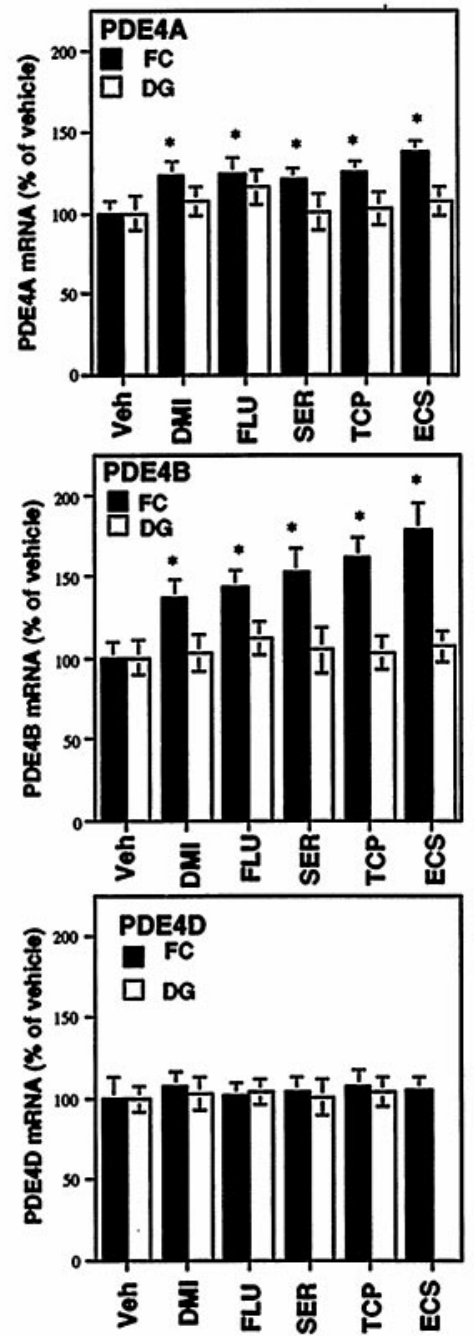

Figure 1. Chronic antidepressant administration increases the expression of PDE4A and PDE4B mRNA in rat frontal cortex. Rats were treated with vehicle or antidepressants as described in Materials and Methods, and levels of PDE4A, PDE4B, and PDE4D mRNA were determined by in situ hybridization analysis. The antidepressants tested included tranylcypromine $(T C P)$, desipramine (DMI), fluoxetine (FLU), sertraline (SER), and electroconvulsive seizure $(E C S)$. Representative autoradiograms are shown, including sections at the level of the frontal cortex $(F C)$ and parietal cortex (Par Ctx), which includes hippocampus. The CA3 and CA1 pyramidal and dentate gyrus $(D G)$ cell layers of the hippocampus are indicated. Levels of mRNA were quantified by densitometry and are shown in the bar graph in the bottom panel. The results are expressed as mean \pm SEM percent of control; $n=4$ per group. ${ }^{*} p<0.05$ compared with control (ANOVA and Fisher's post hoc test).

expression levels of PDE4A, PDE4B, and PDE4D mRNA are relatively similar in this brain region, although levels of PDE4B tend to be slightly higher, as reported previously (Engels et al., 1995). We found that chronic antidepressant treatment significantly increased the levels of PDE4B mRNA in nucleus accumbens (Fig. 2). In contrast, levels of PDE4A and PDE4D were not significantly influenced by the antidepressants tested (see Fig. 2 for representative autoradiograms).

The time course for upregulation of PDE4A and PDE4B mRNA in response to sertraline administration was investigated in further detail (Table 1). One day of sertraline administration did not influence levels of PDE4A or PDE4B mRNA in the frontal cortex or levels of PDE4B mRNA in nucleus accumbens. After $7 \mathrm{~d}$ of drug administration, there was a tendency for levels of PDE4A and PDE4B mRNA to be increased, but these effects were not statistically significant. Only after $14 \mathrm{~d}$ of sertraline administration were levels of PDE4A and PDE4B mRNA significantly increased.
To examine the pharmacological specificity of these effects, the influence of chronic administration of nonantidepressant psychotropic drugs was tested. This included cocaine, a psychostimulant and monoamine reuptake blocker, and haloperidol, an antipsychotic and nonselective dopamine receptor antagonist. Expression of PDE4A in frontal cortex was not influenced by either cocaine or haloperidol treatment (vehicle, $100 \pm 12$; cocaine, $95 \pm 3$; haloperidol, $105 \pm 17$; mean \pm SEM percent of vehicle; $n=4$ per group). Chronic administration of haloperidol did not significantly influence the expression of PDE4B in frontal cortex or nucleus accumbens (Fig. 3). Chronic administration of cocaine did not influence the expression of PDE4B in frontal cortex but did decrease levels of PDE4B mRNA in nucleus accumbens, in contrast to the increase that was observed in response to antidepressant treatment.

The expression pattern of PDE4A, PDE4B, and PDE4D mRNA in the area postrema was also examined. This brain region is known to mediate nausea and emesis, which are major side 
PDE4A
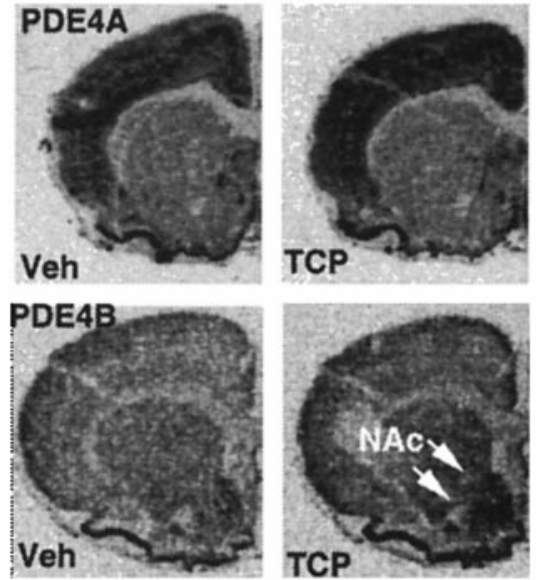

TCP
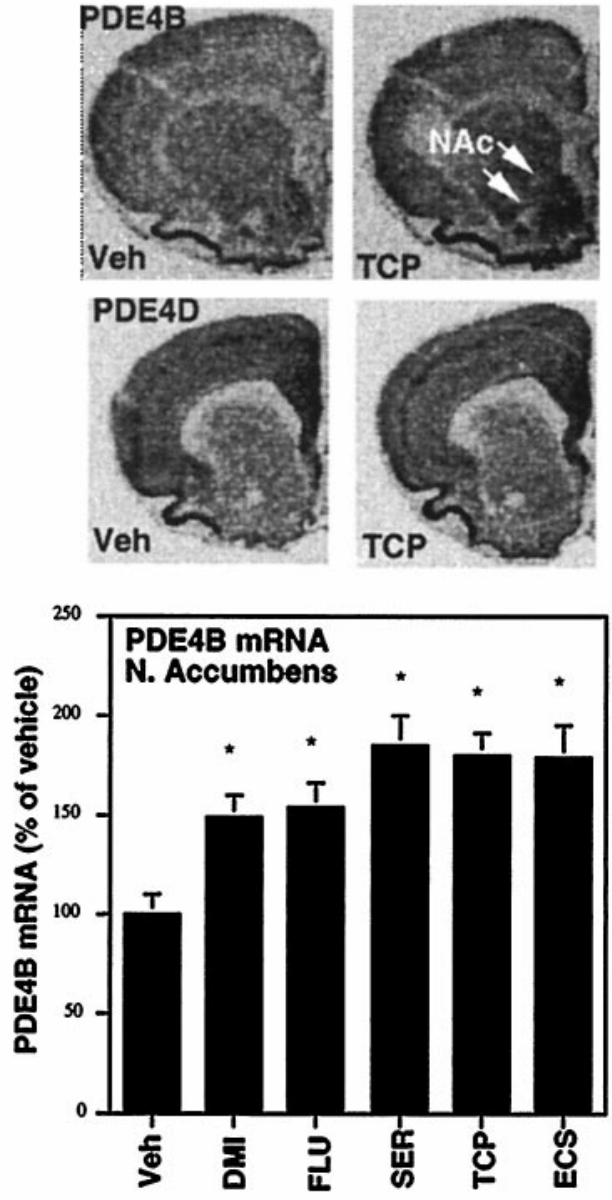

Figure 2. Chronic antidepressant administration increases expression of PDE4B mRNA in the nucleus accumbens. Rats were treated with vehicle or antidepressants as described in Materials and Methods, and levels of PDE4A, PDE4B, and PDE4D mRNA in the nucleus accumbens (NAc) were determined by in situ hybridization analysis. The antidepressants tested were tranylcypromine $(T C P)$, desipramine $(D M I)$, fluoxetine $(F L U)$, sertraline (SER), and electroconvulsive seizure (ECS). Representative autoradiograms are shown in the panels on the left. Levels of mRNA were quantified by densitometry and are shown in the bar graph on the right. Levels of PDE4A and PDE4D were not significantly influenced by any of the treatments tested (data not shown). The results are expressed as mean \pm SEM percent of control; $n=4$ per group. ${ }^{*} p<0.05$ compared with control (ANOVA and Fisher's post hoc test).

effects of PDE4 inhibitors, such as rolipram, that have been tested for the treatment of depression (Hyde et al., 1996). Although these side effects may also be mediated by inhibition of peripheral PDE4, it is possible that central inhibition may also contribute to the nausea and emesis. The area postrema is located on the floor of the fourth ventricle at its most caudal extent and appears just below the cerebellum in cross section (Fig. 4). The relative expression of PDE4A mRNA in the area postrema was not higher than the surrounding brainstem structures. Expression of PDE4B

\begin{tabular}{|c|c|c|c|}
\hline Treatment (d) & $\begin{array}{l}\text { PDE4A Fron- } \\
\text { tal cortex }\end{array}$ & $\begin{array}{l}\text { PDE4B Fron- } \\
\text { tal cortex }\end{array}$ & $\begin{array}{l}\text { PDE4B Nucleus } \\
\text { accumbens }\end{array}$ \\
\hline & \multicolumn{3}{|c|}{ (mean \pm SEM percent of vehicle) } \\
\hline Control & $100 \pm 8$ & $100 \pm 11$ & $100 \pm 10$ \\
\hline \multicolumn{4}{|l|}{ Sertaline } \\
\hline $1 \mathrm{~d}$ & $95 \pm 8$ & $106 \pm 17$ & $103 \pm 15$ \\
\hline $7 \mathrm{~d}$ & $119 \pm 5$ & $127 \pm 12$ & $120 \pm 10$ \\
\hline $14 \mathrm{~d}$ & $121 \pm 7^{*}$ & $184 \pm 15^{*}$ & $152 \pm 16^{*}$ \\
\hline
\end{tabular}

Rats were treated with vehicle or sertraline for 1,7 , or $14 \mathrm{~d}$ as described in Materials and Methods, and levels of PDE4A or PDE4B mRNA were measured by in situ hybridization analysis. Levels of mRNA were quantified in the regions indicated by densitometry. The results are expressed as mean \pm SEM percent of control; $n=3$ or 4 per group. * $p<0.05$ compared with control (ANOVA and Fisher's post hoc test).

mRNA in the area postrema tended to be slightly higher than the very low level of expression in the surrounding brainstem. Levels of PDE4D mRNA in the area postrema appeared to be the highest of the three isoforms, although the background levels were also slightly higher. These findings are preliminary and must be confirmed by immunohistochemical analysis and also by characterization of additional mammalian species. However, the results suggest that PDE4D may be the predominate isoform in the area postrema.

\section{Northern blot analysis of PDE4A and PDE4B mRNA}

Regulation of PDE4A and PDE4B mRNA was further examined by Northern blot analysis of dissected sections of frontal cortex and hippocampus. The PDE4A-specific riboprobe hybridizes with one major mRNA transcript of $\sim 4.5 \mathrm{~kb}$ and the PDE4Bspecific probe with one major transcript of $\sim 4.0 \mathrm{~kb}$ (Fig. 5). Similar mRNA transcripts for PDE4A and PDE4B have been reported previously (Swinnen et al., 1989a). These probes do not hybridize with PDE4D mRNA transcripts, which are $\sim 5.8-7.4 \mathrm{~kb}$ (Swinnen et al., 1989b). These results demonstrate the specificity of the riboprobes for Northern blot, as well as for in situ hybridization analysis.

Chronic administration of tranylcypromine or sertraline significantly increased the expression of PDE4A and PDE4B mRNA in sections of frontal cortex but not hippocampus (Fig. 5). The level of increase observed, twofold to threefold relative to vehicletreated controls, appears to be greater than that observed with in situ hybridization analysis. The reason for this difference is not clear but could be related to the method of analysis or the cellular distribution of mRNA. The time course for sertraline regulation of PDE4B was also examined by Northern blot. Administration of sertraline for 1 or $7 \mathrm{~d}$ did not significantly increase levels of PDE4B mRNA, although there was a tendency for an increase at the longer time point $(1 \mathrm{~d}, 106 \pm 19 ; 7 \mathrm{~d}, 128 \pm 16$; mean \pm SEM percent of vehicle; $n=4$ per group). These data support the results of our in situ hybridization studies and demonstrate that chronic antidepressant administration increases the expression of PDE4A and PDE4B mRNA in cerebral cortex.

\section{Immunoblot analysis of PDE4 isoforms}

Antibodies directed against recombinant PDE4 isoform protein were used for immunoblot analysis. The PDE4A-specific antibody recognizes several proteins in homogenates of frontal cortex, but only two major bands are competed for by preincubation of the antibody with recombinant PDE4A protein (Fig. 6). These pro- 

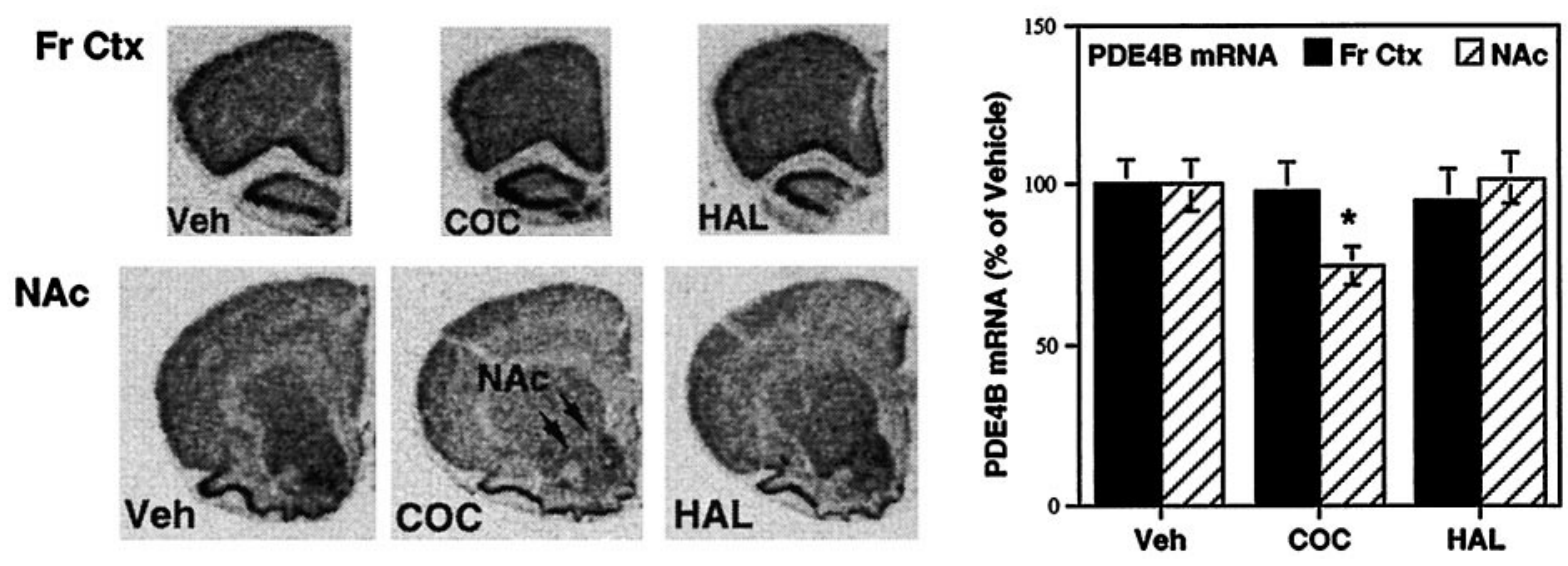

Figure 3. Influence of chronic cocaine or haloperidol administration on expression of PDE4B mRNA. Rats were treated with vehicle (Veh), cocaine $(C O C)$, or haloperidol $(H A L)$ as described in Materials and Methods. Levels of PDE4B mRNA in the frontal cortex (Fr Ctx) and nucleus accumbens $(N A c)$ were determined by in situ hybridization analysis. Representative autoradiograms are shown in the panels on the left. Levels of mRNA were quantified by densitometry and are shown in the bar graph on the right. Levels of PDE4A and PDE4D mRNA were not significantly influenced by any of the treatments tested (data not shown). The results are expressed as mean \pm SEM percent of control; $n=4$ per group. ${ }^{*} p<0.05$ compared with control (ANOVA and Fisher's post hoc test).

Figure 4. Expression of PDE4A, PDE4B, and PDE4D mRNA in area postrema. Levels of PDE4A, PDE4B, and PDE4D mRNA in the area postrema were determined by in situ hybridization analysis. The relative density of PDE4A and PDE4B was relatively low compared with the expression of PDE4D. Representative autoradiograms for each of the PDE4 isoforms are shown. Similar results were obtained in sections taken from three different rats.
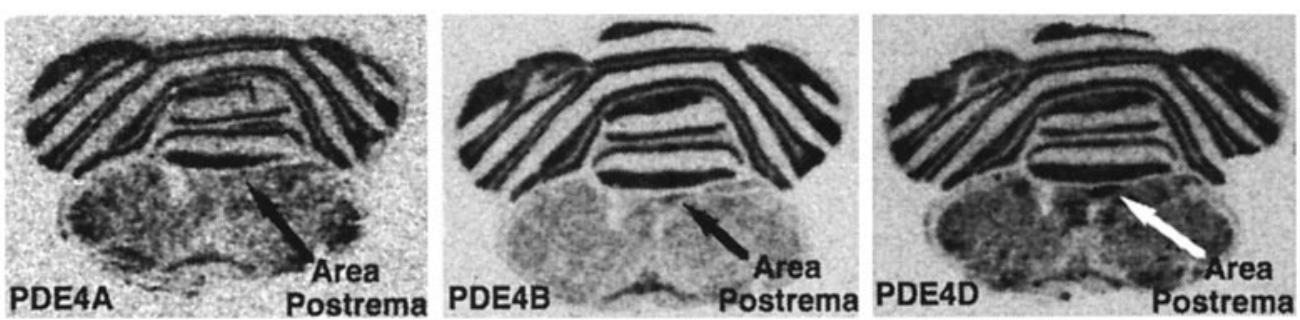

teins are $\sim 75$ and $110 \mathrm{kDa}$ (also referred to as PDE4A1 and PDE4A5) and correspond to the two major PDE4A isoforms reported previously (Cherry and Davis, 1995; McPhee et al., 1995; Shakur et al., 1995; Ye et al., 1997; Iona et al., 1998). The $75 \mathrm{kDa}$ isoform is a minor band that runs just above one of the nonspecific bands. A minor isoform of $\sim 102 \mathrm{kDa}$ has been reported (Ye et al., 1997) but was not observed by Iona et al. (1998). This form of PDE4A was not consistently observed in the present study. Levels of the $110 \mathrm{kDa}$ form were significantly increased in frontal cortex, but not hippocampus, by antidepressant treatment (Fig. 6). Upregulation of the $110 \mathrm{kDa}$ band ranged from $140 \%$ (desipramine) to greater than $200 \%$ (tranylcypromine or ECS) relative to vehicle-treated control. The $75 \mathrm{kDa}$ form was difficult to quantify, because it was not always possible to resolve it from the closely migrating nonspecific protein. These results suggest that upregulation of PDE4A mRNA lead to increased expression of PDE4A protein, as measured by the $110 \mathrm{kDa}$ protein.

Immunoblot analysis of PDE4B demonstrated the presence of three specific forms of 91,83 , and $71 \mathrm{kDa}$. The presence of the 91 $\mathrm{kDa}$ form, also referred to as PDE4B1, in brain was recently reported, but this study only observed trace amounts of the 71 kDa form, also called PDE4B2 (Iona et al., 1998). However, the presence of an mRNA transcript specific to this form was observed in several brain regions, demonstrating its presence in brain (Bolger et al., 1994). The $83 \mathrm{kDa}$ is a relatively minor form that has been observed in a previous study (Iona et al., 1998). Levels of the $91 \mathrm{kDa}$ form were significantly increased in homogenates of frontal cortex but not in hippocampus by chronic anti- depressant treatment. This upregulation was again lowest for desipramine $(133 \%)$ and highest for tranylcypromine and ECS (230 and 290\%, respectively) relative to the vehicle-treated group. The $71 \mathrm{kDa}$ form was also significantly upregulated by chronic antidepressant administration, although the level of regulation was not as great as observed for the $91 \mathrm{kDa}$ protein (sertraline, $134 \pm 16$; tranylcypromine, $150 \pm 20 ; \mathrm{ECS}, 178 \pm 20$; mean \pm SEM percent of vehicle; $n=4 ; p<0.05$; ANOVA and Fisher's post hoc test). There was a tendency for desipramine administration to increase the $71 \mathrm{kDa}$ protein $(127 \pm 19 \%$ of vehicle), but this effect was not significant.

The PDE4D-specific antibody recognized three major proteins of 105,98 , and $93 \mathrm{kDa}$ (also referred to as PDE4D3, PDE4D5, and PDE4D4, respectively) that were blocked by preincubation with recombinant protein. These three forms have been reported previously (Bolger et al., 1997; Iona et al., 1998; Jin et al., 1998). None of these forms of PDE4D were regulated by antidepressant administration, consistent with the lack of effect of these treatments on levels of mRNA. Two additional short forms of PDE4D of 71 and $68 \mathrm{kDa}$, also referred to as PDE4D1 and PDE4D2, have been reported in other tissues but not in brain (Bolger et al., 1997; Iona et al., 1998; Jin et al., 1998), and these forms were not observed in the present study.

\section{DISCUSSION}

The results of this study demonstrate that chronic antidepressant administration increases the expression of PDE4A and PDE4B in cerebral cortex and expression of PDE4B in nucleus accumbens. 

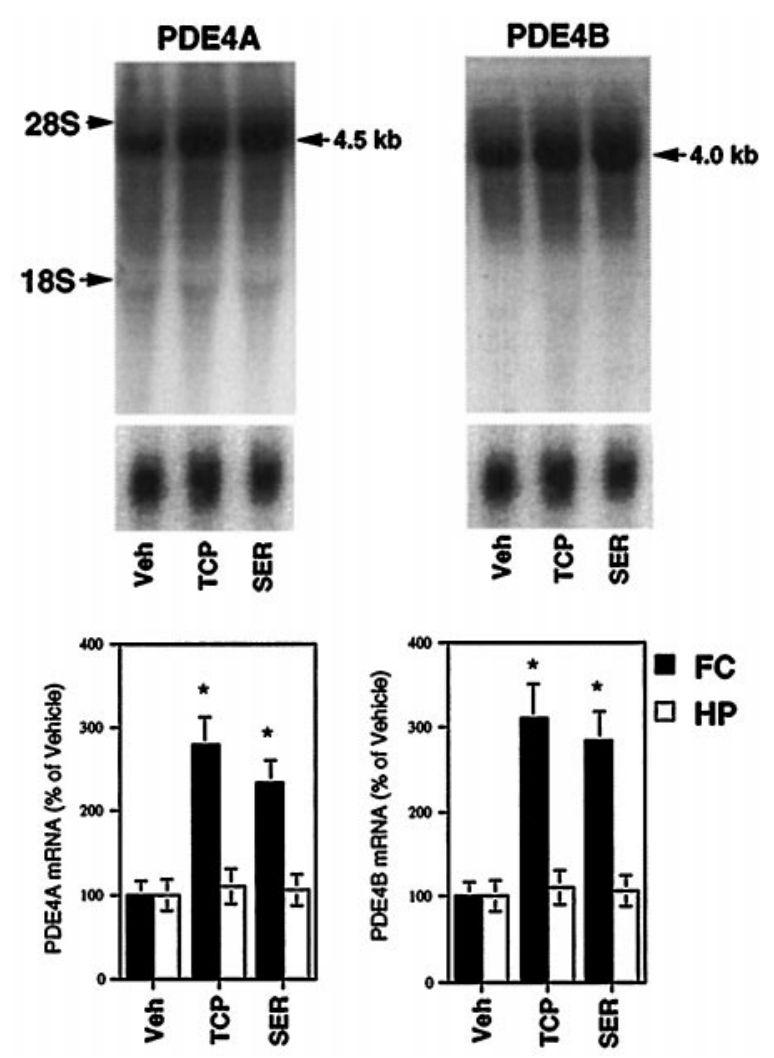

Figure 5. Chronic antidepressant administration increases the expression of PDE4A and PDE4B mRNA in rat frontal cortex as determined by Northern blot analysis. Rats were treated with vehicle (Veh), sertaline $(S E R)$, or tranylcypromine $(T C P)$ for $14 \mathrm{~d}$, and levels of PDE4A and PDE4B mRNA in frontal cortex $(F C)$ and hippocampus $(H P)$ were determined by Northern blot analysis. Representative autoradiograms for frontal cortex are shown in the top panels. Levels of mRNA were quantified by densitometry and are shown in the bar graph in the bottom panel. The results are expressed as mean \pm SEM percent of control; $n=4$ per group. ${ }^{*} p<0.05$ compared with control (ANOVA and Fisher's post hoc test).

In contrast, expression of PDE4D was not influenced by antidepressant administration in either of these brain regions. Upregulation of PDE4A and PDE4B is observed in response to several different classes of antidepressants, including serotonin and norepinephrine selective reuptake inhibitors. In addition, the effect of antidepressants appears to be dependent on chronic administration, because 14 , but not 1 or 7 , d of sertraline treatment increases the expression of PDE4A and PDE4B. Regulation of PDE4A and PDE4B appears also to be specific to antidepressants, because chronic administration of a nonantidepressant psychotropic drug (cocaine or haloperidol) does not upregulate these PDE4 isoforms. Together, the results of the present study suggest that upregulation of PDE4A and PDE4B may represent a compensatory response to antidepressant treatments.

Upregulation of PDE4A and/or PDE4B suggests that antidepressant treatment regulates the cAMP system in cerebral cortex and nucleus accumbens. Brain imaging studies have demonstrated abnormalities in cortical areas in depressed patients, and cerebral cortical dysfunction could contribute to the cognitive deficits associated with depression (Drevets et al., 1997; Mayberg et al., 1997). Although the functional effects of activation of the cAMP system in cerebral cortex are more complex and difficult to determine, studies in hippocampus demonstrate that the cAMP system is involved long-term potentiation, a cellular model of learning and memory. The cAMP system could serve a similar function in cerebral cortex, and activation of this system by antidepressants could contribute to the amelioration of the cognitive abnormalities observed in depression.

The nucleus accumbens is a dopaminergic target area known to play a major role in reward and craving, and an imbalance of this system could contribute to the anhedonia often observed in depression (Serra et al., 1992; Self and Nestler, 1995; Jimerson, 1987). A role for the cAMP system in the function of the nucleus accumbens is supported by recent behavioral studies of cocaine self-administration in rats (Self et al., 1998). These studies demonstrate that activation or inhibition of the cAMP pathway has profound effects on the rewarding actions of psychostimulants. The finding that chronic cocaine treatment downregulates PDE4B mRNA in nucleus accumbens provides further support that the cAMP system is involved in the actions of psychostimulants. In addition to regulation of PDE4B, previous studies have demonstrated that chronic antidepressant administration increases levels of adenylyl cyclase in nucleus accumbens (Serra et al., 1992). These findings suggest that regulation of the cAMP pathway, including PDE4B, by antidepressants may influence reward and motivation and could thereby contribute to the therapeutic action of these treatments.

The mechanisms underlying the upregulation of PDE4A and PDE4B expression in brain may involve activation of gene expression in response to stimulation of the cAMP pathway. This possibility is supported by studies in cultured cells that demonstrate that the cAMP system activates PDE4 gene expression. For example, activation of the cAMP system by stimulation of $\beta$-adrenergic receptors or direct activation of adenylyl cyclase or cAMP-dependent protein kinase increases the expression of PDE4A and PDE4B in human monocytes (Torphy et al., 1995; Verghese et al., 1995; Manning et al., 1996). $\beta$-adrenergic receptor activation also appears to regulate the expression of PDE4A mRNA and enzyme activity in brain, because treatment with a $\beta$-adrenergic receptor antagonist decreases expression of this isoform (Ye and O'Donnell, 1996; Ye et al., 1997). Activation of the cAMP pathway also increases the expression of PDE4B in sertoli cells (Swinnen et al., 1991) and PDE4A in Jurkat lymphoma cells (Engels et al., 1994). Based on these findings, it is not surprising that chronic antidepressant administration increases the expression of PDE4A and PDE4B, because these treatments upregulate the cAMP signaling pathway (Nestler et al., 1989; Perez et al., 1989; Ozawa and Rasenick, 1991; Nibuya et al., 1996) (Fig. 7). However, the exact mechanisms underlying upregulation of PDE4A and PDE4B in brain must be examined. The human and rat PDE4B genes contain potential CRE elements that could mediate increased transcription of these genes in response to activation of the cAMP pathway (Monaco et al., 1994; Huston et al., 1997). Although there are no CRE elements in the human or rat PDE4A genes, only a small portion of the 5' untranslated region of these genes has been sequenced (Bolger et al., 1994; Sullivan et al., 1998). Alternatively, increased mRNA stability could contribute to the upregulation of PDE4A and PDE4B expression.

The regional specificity for regulation of PDE4A and PDE4B and the selectivity for these isoforms, but not PDE4D, are more difficult to explain. Antidepressants are reported to influence the cAMP system in both cerebral cortex (Nestler et al., 1989; Perez et al., 1989; Ozawa and Rasenick, 1991) and hippocampus (Nibuya et al., 1996), suggesting that expression of PDE4A and 

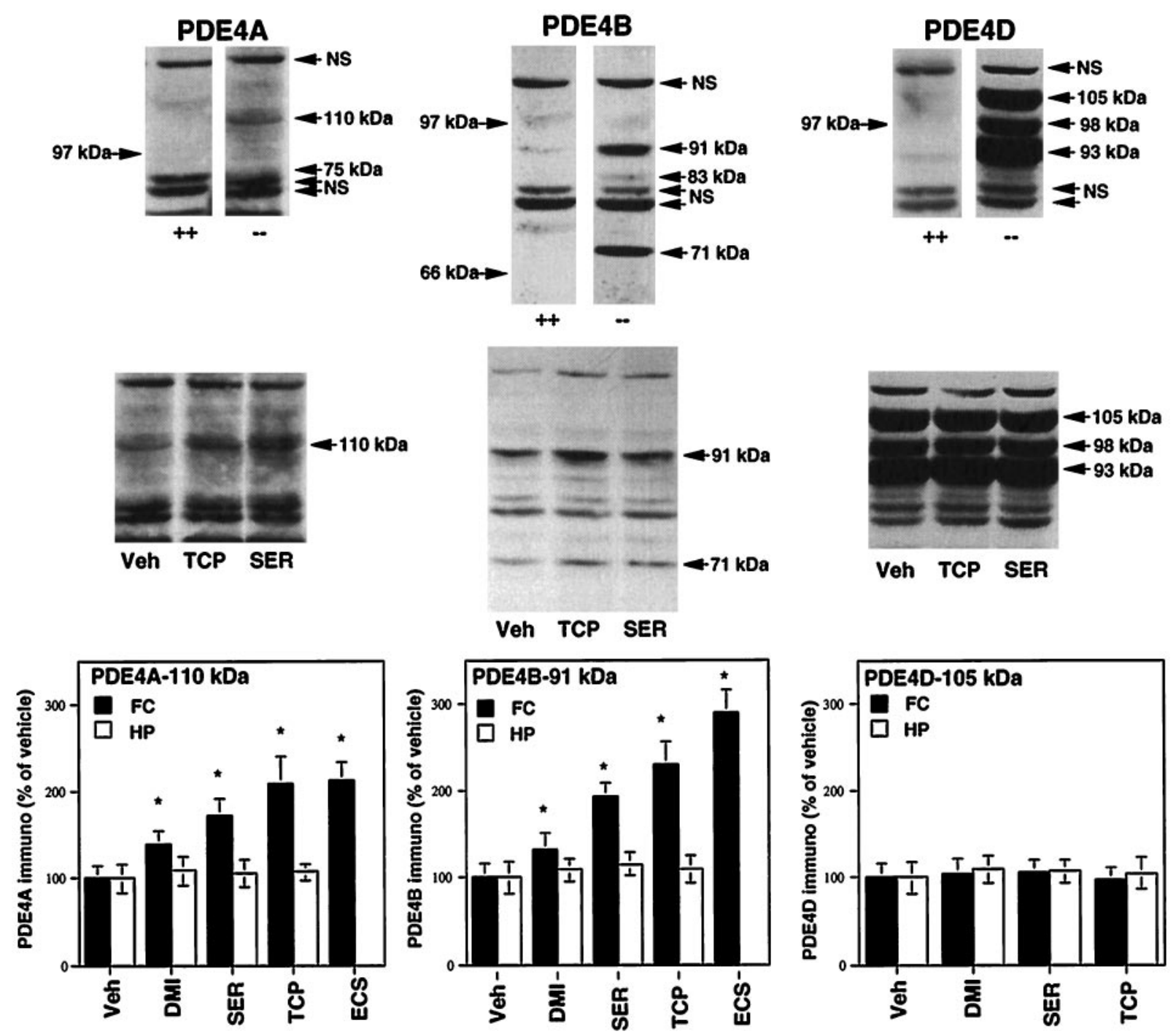

Figure 6. Chronic antidepressant administration increases the expression of PDE4A and PDE4B immunoreactivity in rat frontal cortex. In the top panel, the specificity of the PDE4 antibodies was examined. Each antibody was incubated with the corresponding recombinant protein $(++)$ or with buffer only $(-)$. The antibodies were then used for immunoblot analysis of frontal cortex. Molecular weight markers are shown on the left and the location of immunoreactive bands on the right of each panel. The immunoreactive bands that were not blocked by preincubation with recombinant protein are labeled nonspecific $(N S)$. The PDE4A antibody recognizes one major specific band that is blocked by preincubation with recombinant protein of $\sim 110$ $\mathrm{kDa}$. There is also a minor band of $75 \mathrm{kDa}$ that runs just above the nonspecific band and is therefore difficult to resolve. The PDE4B antibody recognizes three bands that are blocked of 91, 83, and $71 \mathrm{kDa}$. The PDE4D band recognizes three bands that are blocked of 93, 98, and 105 kDa. The middle panel shows representative immunoblots of frontal cortex from vehicle- or antidepressant-treated rats. Levels of immunoreactivity were quantified by densitometry and are shown in the bar graph in the bottom panel. The results are expressed as mean \pm SEM percent of control; $n=4$ per group. ${ }^{*} p<$ 0.05 compared with control (ANOVA and Fisher's post hoc test).

PDE4B would occur in both brain regions. Expression of the short forms of PDE4D (PDE4D1 and PDE4D2) in cultured cells is also increased by activation of the cAMP system (Swinnen et al., 1989b; Swinnen et al., 1991; Sette et al., 1994b), suggesting that this PDE isoform should also be regulated by antidepressants in brain. However, the absence of these forms in brain (Iona et al., 1998; present study) may indicate that this portion of the promoter is silent in brain. Thus, the differences in the cellular expression of the PDE4 isoforms and the presence or absence of transcriptional enhancers or repressors in these cells may mediate the selective regulation of PDE4A and PDE4B by antidepressant treatment in brain. For example, in monocytes, activation of the cAMP system increases the expression of PDE4A and PDE4B but not PDE4C and PDE4D (Torphy et al., 1995; Verghese et al.,
1995; Manning et al., 1996). In Jurkat cells, activation of the cAMP pathway increases expression of PDE4A and PDE4D but not PDE4B and PDE4C (Engels et al., 1994). In SH-SY5Y cells, a neuronal cell line, none of the PDE4 isoforms are regulated by activation of the cAMP system (Engels et al., 1994). The results of the present study suggest that a similar, or even more complex, level of regulatory diversity for the PDE4 genes exists in different cell types in brain.

Although the expression studies indicate that PDE4A and PDE4B are regulated by antidepressants, the results do not exclude the possibility that the activity of PDE4D is regulated. PDE4D is expressed in many limbic brain regions thought to mediate antidepressant actions, including cerebral cortex and hippocampus, and it is possible that phosphorylation-induced 


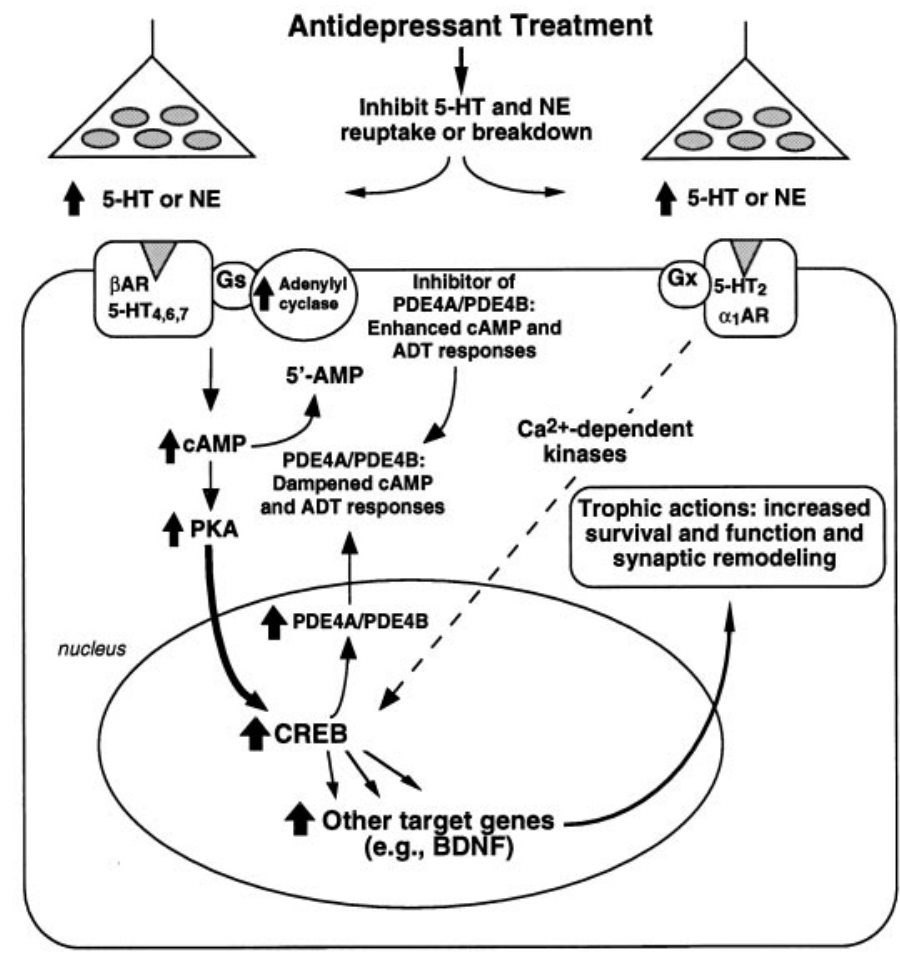

Figure 7. Schematic diagram of postreceptor adaptations of the cAMP pathway observed in response to chronic antidepressant treatment. The cAMP signal transduction pathway is upregulated by chronic antidepressant administration. This includes increased coupling of stimulatory G-protein $(G s)$ to adenylyl cyclase, increased levels of cAMP-dependent protein kinase $(P K A)$, and increased expression of the cAMP response element-binding protein $(C R E B)$. Target genes of CREB (e.g., BDNF) are also upregulated by antidepressant treatment. In addition to regulation of CREB by receptors that are directly coupled to the cAMP pathway (i.e., $\beta \mathrm{AR}, 5-\mathrm{HT}_{4,6,7}$ ), other 5-HT and norepinephrine $(N E)$ receptors that indirectly stimulate $\mathrm{Ca}^{2+}$-dependent kinases may also activate CREB. The results of the present study demonstrate that chronic antidepressant treatment increases the expression of PDE4A and PDE4B. Upregulation of these PDE4 isoforms would be expected to dampen the cAMP response. Although this may be adaptive in normal brain, it could also dampen the antidepressant responses that are mediated by upregulation of this pathway. Selective inhibitors would block the upregulated PDE4A and PDE4B and could thereby enhance the cAMP and antidepressant responses.

activation of this isoform occurs in response to antidepressant treatments. PDE4D is reported to be phosphorylated and activated by cAMP-dependent protein kinase (Sette et al., 1994a), and it is possible that PDE4D is regulated in a similar manner in response to antidepressant treatment. Further studies will be required to determine the influence of antidepressant administration on the phosphorylation state and activity level of PDE4D.

Upregulation of PDE4 gene expression in response to sustained activation of the cAMP pathway is thought to represent a compensatory adaptation that would reduce cAMP levels back to baseline (Conti et al., 1995; Houslay and Milligan, 1997) (Fig. 7). Upregulation of PDE4A and PDE4B could serve a similar function in brain in response to sustained elevation of cAMP levels. If this is the case, it is possible that increased expression of PDE4A and PDE4B could reduce the maximal response to antidepressants (Fig. 7). In addition, regulation of the activity of these PDE isoforms (e.g., via their phosphorylation) could also contribute to the time lag in the therapeutic action of these treatments. These findings raise the possibility that selective inhibitors of the
PDE4A and PDE4B may have antidepressant efficacy and could enhance the response to other classes of antidepressants but without the side effects of nonselective PDE4 inhibitors. The latter possibility is supported by our preliminary finding that PDE4A and PDE4B are expressed at relatively low levels in area postrema, a brain region known to influence nausea, and that levels of PDE4D are expressed at higher levels in this brain region. Based on these findings, it is reasonable to suggest that PDE4A and PDE4B may represent potentially interesting targets for the development of novel therapeutic agents.

\section{REFERENCES}

Beavo JA, Conti M, Heaslip RJ (1994) Multiple cyclic nucleotide phosphodiesterases. Mol Pharmacol 46:399-405.

Beitner-Johnson D, Guitart X, Nestler EJ (1992) Neurofilament proteins and the mesolimbic dopamine system: common regulation by chronic morphine and chronic cocaine in the rat ventral tegmental area. J Neurosci 12:2165-2176.

Bobon D, Breulet M, Gerard-Vandenhove MA, Guilot-Goffioul F, Plonteux G, Sastre-y-Hernandez M, Schratzer M, Troisfontaines B, VovFrenckell R, Wachtel H (1988) Is phosphodiesterase inhibition a new mechanism of antidepressant action? A double blind double-dummy study between rolipram and desipramine in hospitalized major and/or endogenous depressives. Eur Arch Psychiatry Neurol Sci 238:2-6.

Bolger GB, Rodgers L, Riggs M (1994) Differential CNS expression of alternative mRNA isoforms of the mammalian genes encoding cAMPspecific phosphodiesterases. Gene 149:237-244.

Bolger GB, Erdogan S, Jones RE, Loughnew K, Scotland G, Hoffmann R, Wilkinson I, Farrell C, Houslay MD (1997) Characterization of five different proteins produced by alternatively spliced mRNAs from the human cAMP-specific phosphodiesterase PDE4D gene. Biochem J 328:539-548.

Cherry JA, Davis Rl (1995) A mouse homolog of dunce, a gene important for learning and memory in Drosophila, is preferentially expressed in olfactory receptor neurons. J Neurobiol 28:102-113.

Conti M, Jin S-LC (1999) The molecular biology of cyclic nucleotide phosphodiesterases. Prog Nucleic Acid Res Mol Biol, in press.

Conti M, Nemoz G, Sette C, Vicini E (1995) Recent progress in understanding the hormonal regulation of phosphodiesterases. Endocr Rev 16:370-389.

Drevets WC, Price JL, Simpson Jr JR, Todd RD, Reich T, Vannier M, Raichle ME (1997) Subgenual prefrontal cortex abnormalities in mood disorders. Nature 386:824-827.

Duman RS, Heninger GR Nestler, EJ (1997) A molecular and cellular theory of depression. Arch Gen Psychiatry 54:597-606.

Engels P, Fichtel K, Lubbert H (1994) Expression and regulation of human and rat phosphodiesterase type IV isogenes. FEBS Lett 350:291-295.

Engels P, Abdel'Al S, Hulley P, Lübbert H (1995) Brain distribution of four rat homologues of the Drosophila dunce cAMP phosphodiesterase. J Neurosci Res 41:169-178.

Fleischhacker WW, Hinterhuber H, Bauer H, Pflug B, Berner P, Simhandl C, Wilf R, Gerlach W, Jaklitsch H, Sastre-y-Hernandez M, Schmeding-Wiegel H, Sperner-Unterweger B, Voet B, Schubert H (1992) A multicenter double-blind study of three different doses of the new cAMP-phosphodiesterase inhibitor rolipram in patients with major depressive disorder. Neuropsychobiology 26:59-64.

Griebel G, Misslin R, Vogel E, Bourguignon J (1991) Behavioral effects of rolipram and structurally related compounds in mice: behavioral sedation of cAMP phosphodiesterase inhibitors. Pharmacol Biochem Behav 39:321-323.

Horowski R, Sastre-Y-Hernandez M (1985) Clinical effects of the neurotrophic selective cAMP phosphodiesterase inhibitor rolipram in depressed patients: global evaluation of the preliminary reports. Curr Ther Res 38:23-29.

Houslay MD, Milligan G (1997) Tailoring cAMP signalling responses through isoform multiplicity. Trends Biochem Sci 22:217-224.

Huston E, Lumb S, Russell A, Catterall C, Ross AH, Steele MR, Bolger GB, Perry MJ, Owens RJ, Houslay MD (1997) Molecular cloning and transient expression in COS7 cells of a novel human PDE4B cAMPspecific phosphodiesterase, HSPDE4B3. Biochem J 328:549-558.

Hyde TM, Knable MB, Murray AM (1996) Distribution of dopamine 
D1-D4 receptor subtypes in human dorsal vagal complex. Synapse 24:224-232.

Iona S, Cuomo M, Bushnik T, Naro F, Sette C, Hess M, Shelton ER, Conti M (1998) Characterization of the rolipram-sensitive, cyclic AMP-specific phosphodiesterases: identification and differential expression of immunologically distinct forms in the rat brain. Mol Pharmacol 53:23-32.

Jimerson DC (1987) Role of dopamine mechanisms in the affective disorders. In: Psychopharmacology: the third generation of progress (Meltzer HY, ed), pp 505-511. New York: Raven.

Jin S-LC, Bushnik T, Lan L, Conti M (1998) Subcellular localization of rolipram-sensitive cAMP-specific phosphodiesterases: differential targeting and activation of the splicing variants derived from the PDE4D gene. J Biol Chem 273:19672-19678.

Malison R, Price LH, Nestler EJ, Heninger GR, Duman RS (1997) Efficacy of Papaverine addition in treatment-refractory major depression. Am J Psychiatry 154:579-580.

Manning CD, McLaughlin M, Livi GP, Cieslinski LB, Torphy TJ, Barnette MS (1996) Prolonged $\beta$ adrenoceptor stimulation up-regulates cAMP phosphodiesterase activity in human monocytes by increasing mRNA and protein for phosphodiesterases 4A and 4B. J Pharmacol Exp Ther 276:810-818.

Mayberg HS, Brannan SK, Mahurin RK, Jerabek PA, Brickman JS, Tekell JL, Silva A, McGinnis S, Glass TG, Martin CC, Fox PT (1997) Cingulate function in depression: a potential predictor of treatment response. NeuroReport 8:1057-1061.

McPhee I, Polley L, Lobban M, Bolger G, Houslay Sr MD (1995) Identification, characterization and regional distribution in brain of RPDE-6 (RNDPDE4A5), a novel splice variant of the PDE4A cyclic AMP phosphodiesterase family. Biochem J 310:965-974.

Monaco L, Vicini E, Conti M (1994) Structure of two rat genes coding for closely related rolipram-sensitive cAMP phosphodiesterases. J Biol Chem 269:347-357.

Nestler EJ, Terwilliger RZ, Duman RS (1989) Chronic antidepressant administration alters the subcellular distribution of cyclic AMPdependent protein kinase in rat frontal cortex. J Neurochem 53:1644-1647.

Nibuya M, Morinobu S, Duman RS (1995) Regulation of BDNF and trkB mRNA in rat brain by chronic electroconvulsive seizure and antidepressant drug treatments. J Neurosci 15:7539-7547.

Nibuya M, Nestler EJ, Duman RS (1996) Chronic antidepressant administration increases the expression of cAMP response element binding protein (CREB) in rat hippocampus. J Neurosci 16:2365-2372.

O'Donnell JM (1993) Antidepressant-like effects of rolipram and other inhibitors of cyclic AMP phosphodiesterase on behavior maintained by differential reinforcement of low response rate. J Pharmacol Exp Ther 264:1168-1178.

Ozawa H, Rasenick MM (1991) Chronic electroconvulsive treatment augments coupling of the GTP-binding protein Gs to the catalytic moiety of adenylyl cyclase in a manner similar to that seen with chronic antidepressant drugs. J Neurochem 56:330-338.

Perez J, Tinelli D, Brunello N, Racagni G (1989) cAMP-dependent phosphorylation of soluble and crude microtubule fractions of rat cerebral cortex after prolonged desmethylimipramine treatment. Eur J Pharmacol 172:305-316.

Perez J, Tinelli D, Bianchi E, Brunello N, Racagni G (1991) cAMP binding proteins in the rat cerebral cortex after administration of selective 5-HT and NE reuptake blockers with antidepressant activity. Neuropsychopharmacology 4:57-64.

Self DS, Nestler EJ (1995) Molecular mechanisms of drug reinforcement and addiction. Annu Rev Neurosci 18:463-495.

Self DW, Genova LM, Hope BT, Barnhart WJ, Spencer JJ, Nestler EJ (1998) Involvement of cAMP-dependent protein kinase in the nucleus accumbens in cocaine self-administration and relapse of cocaineseeking behavior. J Neurosci 18:1848-1859.

Serra G, Collu M, D’Aquila, Gessa GL (1992) Role of the mesolimbic dopamine system in the mechanism of action of antidepressants. Pharmacol Toxicol 71:72-85.

Sette C, Iona S, Conti M (1994a) The short-term activation of a rolipram-sensitive cAMP specific phosphodiesterase by TSH in thyroid FRTL-5 cells is mediated by a cAMP-dependent phosphorylation. J Biol Chem 269:9245-9252.

Sette C, Vicini E, Conti M (1994b) The rat PDE3/IVd phosphodiesterase gene codes for multiple proteins differentially activated by cAMPdependent protein kinase. J Biol Chem 269:18271-18274.

Shakur Y, Wilson M, Pooley L, Lobban M, Griffins SL, Campbell AM, Beattie J, Daly C, Houslay MD (1995) Identification and characterization of the type-IVA cyclic AMP-specific phosphodiesterase RD1 as a membrane-bound protein expressed in cerebellum. Biochem $\mathbf{J}$ 306:801-809.

Sullivan M, Rena G, Begg F, Gordon L, Olsen AS, Houslay MD (1998) Identification and characterization of the human homologue of the short PDE4A cAMP-specific phosphodiesterase RD1 (PDE4A1) by analysis of human HSPDE4A gene locus located at chromosome 19p13.2. Biochem J 333:693-703.

Swinnen J, Joseph DR, Conti M (1989a) Molecular cloning of rat homologues of the Drosophila melanogaster dunce cAMP phosphodiesterase; evidence for a family of genes. Proc Natl Acad Sci USA 86:5325-5329.

Swinnen JV, Joseph DR, Conti M (1989b) The mRNA encoding a high-affinity cAMP phosphodiesterase is regulated by hormones and cAMP. Proc Natl Acad Sci USA 86:8197-8201.

Swinnen JV, Tsikalas KE, Conti M (1991) Properties and hormonal regulation of two structurally related cAMP phosphodiesterases from the rat sertoli cell. J Biol Chem 266:18370-18377.

Torphy TJ, Zhou HL, Foley JJ, Sarau HM, Manning CD, Barnette MS (1995) Salbutamol upregulates PDE4 activity and induces a heterologous desensitization of U937 cells to prostaglandin E2. J Biol Chem 270:23598-23604.

Verghese MW, McConnell RT, Lenhard JM, Hamacher L, Jin S-L (1995) Regulation of distinct cyclic AMP-specific phosphodieserase (phosphodiesterase type 4) isozymes in human monocytic cells. Mol Pharmacol 47:1164-1171.

Wachtel H, Schneider HH (1986) Rolipram, a novel antidepressant drug, reverses the hypothermia and hypokinesia of monoaminedepleted mice by an action beyond postsynaptic monoamine receptors. Neuropharmacology 25:1119-1126.

Ye Y, O’Donnell JM (1996) Diminished noradrenergic stimulation reduces the activity of rolipram-sensitive, high-affinity cyclic AMP phosphodiesterase in rat cerebral cortex. J Neurochem 66:1894-1902.

Ye Y, Conti M, Houslay, MD, Faroqui SM, Chen M, O’Donnell JM (1997) Noradrenergic activity differentially regulates the expression of rolipram-sensitive, high-affinity cyclic AMP phosphodiesterase (PDE4) in rat brain. J Neurochem 69:2397-2404. 